\title{
Inadequate Hydration, BMI, and Obesity Among US Adults: NHANES 2009-2012
}

\author{
Tammy Chang, $M D, M P H, M S^{1-3}$ \\ Nithin Ravi, MPH \\ Melissa A. Plegue, $M A^{1}$ \\ Kendrin R. Sonneville, ScD, RD ${ }^{4}$ \\ Matthew M. Davis, MD, MAPP $P^{3,5,6}$
}

'Department of Family Medicine, University of Michigan, Ann Arbor, Michigan

${ }^{2}$ Medical School, University of Michigan, Ann Arbor, Michigan

${ }^{3}$ Institute for Healthcare Policy and Innovation, University of Michigan, Ann Arbor, Michigan

${ }^{4}$ Department of Nutritional Sciences, School of Public Health, University of Michigan, Ann Arbor, Michigan

${ }^{5}$ Departments of Pediatrics and Internal Medicine, University of Michigan Ann Arbor, Michigan

${ }^{6}$ Department of Health Management and Policy, School of Public Health, University of Michigan, Ann Arbor, Michigan

Conflicts of interest: authors report none.

\section{CORRESPONDING AUTHOR}

Tammy Chang, MD, MPH, MS Department of Family Medicine Building 14, Room 107 University of Michigan 2800 Plymouth Rd Ann Arbor, MI 48109-2800 tachang@med.umich.edu

\begin{abstract}
PURPOSE Improving hydration is a strategy commonly used by clinicians to prevent overeating with the goal of promoting a healthy weight among patients. The relationship between weight status and hydration, however, is unclear. Our objective was to assess the relationship between inadequate hydration and BMI and inadequate hydration and obesity among adults in the United States.
\end{abstract}

METHODS Our study used a nationally representative sample from the National Health and Nutrition Examination Survey (NHANES) 2009 to 2012, and included adults aged 18 to 64 years. The primary outcome of interest was body mass index (BMI), measured in continuous values and also categorized as obese (BMI 230 ) or not (BMI <30). Individuals with urine osmolality values of $800 \mathrm{mOsm} /$ $\mathrm{kg}$ or greater were considered to be inadequately hydrated. Linear and logistic regressions were performed with continuous BMI and obesity status as the outcomes, respectively. Models were adjusted for known confounders including age, race/ethnicity, sex, and income-to-poverty ratio.

RESULTS In this nationally representative sample $(n=9,528$; weighted $n=193.7$ million), $50.8 \%$ were women, $64.5 \%$ were non-Hispanic white, and the mean age was 41 years. Mean urine osmolality was $631.4 \mathrm{mOsm} / \mathrm{kg}(\mathrm{SD}=236.2$ $\mathrm{mOsm} / \mathrm{kg}) ; 32.6 \%$ of the sample was inadequately hydrated. In adjusted models, adults who were inadequately hydrated had higher BMIs $\left(1.32 \mathrm{~kg} / \mathrm{m}^{2} ; 95 \% \mathrm{Cl}\right.$, $0.85-1.79 ; P<.001)$ and higher odds of being obese $(\mathrm{OR}=1.59 ; 95 \% \mathrm{Cl}, 1.35$ 1.88; $P<.001)$ compared with hydrated adults.

CONCLUSION We found a significant association between inadequate hydration and elevated BMI and inadequate hydration and obesity, even after controlling for confounders. This relationship has not previously been shown on a population level and suggests that water, an essential nutrient, may deserve greater focus in weight management research and clinical strategies.

Ann Fam Med 2016;14:320-324. doi: 10.1370/afm.1951.

\section{INTRODUCTION}

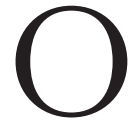
besity continues to be a prevalent, debilitating, and costly chronic disease in most high-income countries. ${ }^{1}$ The drivers of obesity are multifactorial and represent a major clinical challenge in both prevention and management. ${ }^{2,3}$ In addition to replacing sugar-sweetened beverages with water, improving overall hydration is a strategy commonly used to prevent overeating, with the goal of promoting a healthy weight among patients. ${ }^{4-6}$ For example, counseling patients to first drink water when they have the urge to eat, as they may actually be thirsty rather than hungry, is a recommendation clinicians give patients and is advice readily found in lay media.

Water intake as a weight loss tool, however, is not an evidence-based recommendation. Recent studies have shown mixed results, likely because of limitations in the measurement of hunger and thirst, as well as the numerous social, cognitive, sensory, and logistical factors that influence eating and drinking behaviors. ${ }^{5}$ Some studies suggest that water intake may be a promising target for obesity prevention and treatment, whereas 
other studies report an association between obesity and greater water intake. ${ }^{7,8}$

A recent systematic review reported contradictory findings between water intake and obesity among the 6 cross-sectional studies investigated, with some studies even showing a direct relationship between water intake and obesity. ${ }^{8}$ The authors hypothesized that obese individuals may consume food with higher salt content, driving the need for increased water intake to balance the renal solute load. ${ }^{8}$ Although these crosssectional studies of water intake and obesity have shown mixed results, results from recent longitudinal studies and randomized controlled trials indicate the potential for water to prevent and treat obesity effectively. ${ }^{4,9}$ Findings from 3 prospective cohort studies (the Nurses' Health Study I and II, and the Health Professionals Follow-Up Study) indicate that greater water intake is inversely associated with weight gain. ${ }^{10}$

Among these studies, water intake has been the outcome of interest. ${ }^{4,8-10}$ Urine osmolality, however, is a more effective measure of hydration than water intake alone, as it accounts for water and solutes acquired in food and other beverages. ${ }^{11}$ Urine osmolality also measures daily water intake more accurately because it is an objective laboratory measurement that is not subject to recall bias. In 2009, the National Health and Nutrition Examination Survey (NHANES) added urine osmolality as a laboratory test for its sample. To date, no population-level studies have investigated the relationship between adequate hydration, as measured by urine osmolality, and obesity. The aim of this study was to use the NHANES to assess the relationship between urine osmolality as a marker for hydration and obesity (based on body mass index, BMI) among adults in the United States.

\section{METHODS}

The NHANES is a program of studies designed to assess the health and nutritional status of adults and children in the United States. This survey is unique in that it combines interviews and physical examinations. Data from the 2 most recent NHANES cohorts (2009 to 2010 and 2011 to 2012) were used for all analyses. ${ }^{12}$ Adults aged 18 to 64 years with complete medical examination data were included in the analysis. To make a collection of participants selected under the complex NHANES survey design representing the US noninstitutionalized civilian population, each sampled person is assigned a numerical sample weight. All analyses were performed using appropriate complex survey weights with STATA 13.1 (StataCorp LP). The University of Michigan institutional review board determined this study to be not regulated.
The primary outcome of interest was BMI $\left(\mathrm{kg} / \mathrm{m}^{2}\right)$, which was used to further categorize individuals as obese (BMI $\geq 30$ ) or not (BMI <30). ${ }^{13}$ Urine osmolality information collected at the medical examination was used to determine hydration status. Consistent with previous studies and recommendations, individuals with values of $800 \mathrm{mOsm} / \mathrm{kg}$ or greater were considered inadequately hydrated. ${ }^{11,14-16}$ Bivariate associations between hydration and covariates were performed using independent samples $t$ test and Pearson $\chi^{2}$, as appropriate. Models were adjusted for known confounders including age, race/ethnicity, sex, and income-to-poverty ratio. ${ }^{17,18}$ To determine income-to-poverty ratio, participants were asked to report the total (annual) income for themselves and for other members of their family. Family income was then divided by the poverty threshold, which is adjusted for family size and is updated annually for inflation. An income-to-poverty ratio less than 1 indicates that the family is below the poverty threshold.

Linear and logistic regressions were performed with continuous BMI and obesity status (obese/not obese) as the outcomes, respectively. To determine whether associations between BMI and hydration status changed with age, interactions between hydration status and age were investigated in both the linear and logistic regression models. All findings are reported with sampling weights applied, unless otherwise noted.

To ensure that results were not influenced by factors known to alter urine osmolality, a sensitivity analysis was performed on the final models. We identified individuals who had a known diagnosis of diabetes, who had an elevated glycohemoglobin level $(6.5 \%$ or greater), or who were currently prescribed a diuretic and reestimated the final models excluding these cases.

Of note, hydration status is dependent on water intake via consumption of food and fluids, as well as on water production, which is influenced by physical activity among other factors, and they are intermediate in the proposed pathway linking BMI and hydration. Accordingly, we did not adjust for fluid intake or physical activity to avoid overadjustment in our models.

\section{RESULTS}

After combining data from the NHANES 2009-2010 and 2011-2012 surveys, we had an unweighted sample size of 9,528 individuals (weighted $\mathrm{n}=193.7$ million) aged 18 to 64 years with complete medical examination data. Table 1 displays the demographic characteristics of the sample. Approximately $50.8 \%$ were women, $64.5 \%$ were non-Hispanic white, their mean age was 41.1 years.

The mean urine osmolality was $631.4 \mathrm{mOsm} / \mathrm{kg}$ $(\mathrm{SD}=236.2 \mathrm{mOsm} / \mathrm{kg})$, with $32.6 \%$ inadequately 
hydrated based on a urine osmolality of $800 \mathrm{mOsm} / \mathrm{kg}$ or greater. In bivariate analyses, hydration status was significantly associated with age, race/ethnicity, sex, income-to-poverty ratio, and BMI (Table 2).

In multivariable analyses, hydration status was significantly associated with BMI outcomes in both linear and logistic regression models (Table 3). Adults who were inadequately hydrated had a mean BMI of $1.32 \mathrm{~kg} / \mathrm{m}^{2}\left(95 \% \mathrm{CI}, 0.85-1.79 \mathrm{~kg} / \mathrm{m}^{2}{ }_{i} P<.001\right)$ more than hydrated individuals, on average. The odds of being obese were 1.59 times higher for inadequately hydrated individuals compared with hydrated individuals $(95 \% \mathrm{CI}, 1.35-1.88 ; \mathrm{P}<.001)$.

As expected, race/ethnicity, income-to-poverty ratio, and age were also significantly associated with BMI outcomes in adjusted models. Mexican Americans and non-Hispanic blacks were more likely to be obese and have higher BMIs than non-Hispanic whites, whereas other races were less likely. Older adults also had higher BMIs and were more likely to be obese than younger adults. Individuals with higher incometo-poverty ratios were significantly less likely to have higher BMIs and less likely to be obese than individuals with lower income-to-poverty ratios. No significant interactions were found between hydration status and age in either linear or logistic regressions.

In this sample, 1,536 individuals had known diabetes $(\mathrm{n}=807)$, had an elevated glycohemoglobin $(n=242)$, or were prescribed a diuretic $(n=487)$. A sensitivity analysis that used models excluding this subset of individuals resulted in findings similar to those of the models above. Inadequately hydrated individuals had higher mean BMIs $\left(1.44 \mathrm{~kg} / \mathrm{m}^{2} ; 95 \%\right.$ $\left.\mathrm{CI}, 1.02-1.87 \mathrm{~kg} / \mathrm{m}^{2} ; \mathrm{P}<.001\right)$ and were also more likely to be obese (adjusted odds ratio $=1.67 ; 95 \% \mathrm{CI}, 1.40-1.99$; $P<.001)$ than adequately hydrated individuals. Race, age, and incometo-poverty ratio effects on BMI and obesity were also similar in models excluding this group (data not shown).

\section{DISCUSSION}

In this nationally representative, recent sample of US adults, inadequate hydration was associated with higher BMI and obesity among adults aged 18 to 64 years. Our study highlights a novel relationship between hydration and BMI that may have important clinical implications.
Table 1. Demographic Characteristics of US Adults Aged 18 to 64 Years, NHANES 2009-2012

\begin{tabular}{|c|c|c|}
\hline Characteristic & Unweighted & Weighted \\
\hline \multicolumn{3}{|l|}{ Age, $y^{a}$} \\
\hline $18-24$, No (\%) & $1,653(17.4)$ & 14.9 \\
\hline $25-30$, No (\%) & $1,136(11.9)$ & 12.8 \\
\hline $31-40$, No (\%) & $1,942(20.4)$ & 20.4 \\
\hline $41-50$, No $(\%)$ & $1,951(20.5)$ & 22.3 \\
\hline 51-64, No (\%) & $2,846(29.9)$ & 29.6 \\
\hline Mean (SD), y & $40.8(14.1)$ & $41.1(11.7)$ \\
\hline \multicolumn{3}{|l|}{ Race/ethnicitya } \\
\hline Mexican American, No (\%) & $1,541(16.2)$ & 9.2 \\
\hline Other Hispanic, No (\%) & $1,019(10.7)$ & 6.2 \\
\hline Non-Hispanic white, No (\%) & $3,645(38.3)$ & 64.5 \\
\hline Non-Hispanic black, No (\%) & $2,201(23.1)$ & 12.2 \\
\hline Other, No $(\%)^{\mathrm{b}}$ & $1,122(11.8)$ & 7.9 \\
\hline \multicolumn{3}{|l|}{ Sex } \\
\hline Male, No (\%) & $4,656(48.9)$ & 49.2 \\
\hline Female, No (\%) & $4,872(51.1)$ & 50.8 \\
\hline \multicolumn{3}{|l|}{ Income-to-poverty ratioc } \\
\hline $\begin{array}{l}<1(<100 \% \text { federal } \\
\text { poverty level) }\end{array}$ & $2,308(26.6)$ & 17.9 \\
\hline Mean (SD) ratio & $2.4(1.7)$ & $2.9(1.4)$ \\
\hline \multicolumn{3}{|c|}{ Note: unweighted $\mathrm{N}=9,528$; weighted $\mathrm{n}=193.7$ million. } \\
\hline \multicolumn{3}{|c|}{$\begin{array}{l}\text { a } N=9,528 . \\
{ }^{b} \text { Includes Asian, Native American, multiracial, and all other populations. } \\
{ }^{\mathrm{C}} \mathrm{n}=8,680 .\end{array}$} \\
\hline
\end{tabular}

Table 2. Bivariate Relationships Between Hydration Status and Participants' Characteristics

\begin{tabular}{|c|c|c|}
\hline Characteristic & $\begin{array}{l}\text { Adequately Hydrateda } \\
(67.4 \% \text {, Weighted) }\end{array}$ & $\begin{array}{l}\text { Inadequately Hydrated } \\
(32.6 \% \text {, Weighted })\end{array}$ \\
\hline Age, mean (SD), $y^{c}$ & $43(12)$ & $37(12)$ \\
\hline \multicolumn{3}{|l|}{ Race/ethnicity } \\
\hline Mexican American, \% & 7.8 & 12.0 \\
\hline Other Hispanic, \% & 5.4 & 7.8 \\
\hline Non-Hispanic white, \% & 68.4 & 57.8 \\
\hline Non-Hispanic black, \% & 10.4 & 15.0 \\
\hline Other, \%e & 8.1 & 7.5 \\
\hline \multicolumn{3}{|l|}{$\operatorname{Sex}^{d}$} \\
\hline Male, \% & 46.0 & 59.1 \\
\hline Female, \% & 54.0 & 40.9 \\
\hline $\begin{array}{l}\text { Income-to-poverty ratio, } \\
\text { mean (SD) }\end{array}$ & $3.0(1.5)$ & $2.8(1.5)$ \\
\hline $\mathrm{BMI}$, mean $(\mathrm{SE})^{\mathrm{c}, \mathrm{d}}$ & $28.3(0.15)$ & $29.2(0.20)$ \\
\hline Obese, $\%^{f}$ & 67.7 & 59.7 \\
\hline Not obese, $\%^{g}$ & 32.3 & 40.3 \\
\hline \multicolumn{3}{|c|}{$\mathrm{BMI}=$ body mass index; $\mathrm{SE}=$ standard error. } \\
\hline $\begin{array}{l}\text { a Urine osmolality <800 mOsn } \\
\text { b Urine osmolality } \geq 800 \mathrm{mOsm} \\
\text { 'Compared using independen } \\
\text { ' Compared using Pearson } \chi^{2} \mathrm{t} \\
{ }^{\mathrm{e}} \text { Includes Asian, Native Ameri } \\
{ }^{\mathrm{f}} \mathrm{BMI} \geq 30 \text {. } \\
{ }^{9} \mathrm{BMI}<30 .\end{array}$ & $\begin{array}{l}\text { lkg. } \\
\text { kg. } \\
\text { samples } t \text { test, all } P<.001 \text {. } \\
\text { st, all } P<.001 \text {. } \\
\text { in, multiracial, and all other popula }\end{array}$ & ons. \\
\hline
\end{tabular}


Table 3. Results of Linear and Logistic Regression Models

\begin{tabular}{|c|c|c|}
\hline Variable & $\begin{array}{c}\text { Linear Regression: } \\
\text { Continuous BMI } \\
\beta(95 \% \mathrm{Cl})\end{array}$ & $\begin{array}{c}\text { Logistic Regression: } \\
\text { BMI } \geq 30 \\
\text { OR }(95 \% \mathrm{Cl})\end{array}$ \\
\hline Inadequate hydration & $1.32(0.85 \text { to } 1.79)^{a}$ & $1.59(1.35 \text { to } 1.88)^{\mathrm{a}}$ \\
\hline \multicolumn{3}{|l|}{ Sex } \\
\hline Female & Reference & Reference \\
\hline Male & $0.21(-0.12$ to 0.53$)$ & 1.09 (0.96 to 1.25$)$ \\
\hline \multicolumn{3}{|l|}{ Race/ethnicity } \\
\hline Non-Hispanic white & Reference & Reference \\
\hline Mexican American & $1.02(0.42 \text { to } 1.62)^{b}$ & $1.40(1.17 \text { to } 1.66)^{\mathrm{a}}$ \\
\hline Other Hispanic & $0.39(-0.17$ to 0.95$)$ & 1.15 (0.94 to 1.42$)$ \\
\hline Non-Hispanic black & $2.32(1.76 \text { to } 2.88)^{\mathrm{a}}$ & $1.76(1.48 \text { to } 2.09)^{a}$ \\
\hline Other & $-2.11(-2.73 \text { to }-1.49)^{\mathrm{a}}$ & $0.49(0.38 \text { to } 0.62)^{\mathrm{a}}$ \\
\hline Income-to-poverty ratio & $-0.28(-0.44 \text { to }-0.13)^{b}$ & $0.93(0.89 \text { to } 0.97)^{b}$ \\
\hline Age & $0.09(0.07 \text { to } 0.11)^{a}$ & $1.02(1.01 \text { to } 1.03)^{\mathrm{a}}$ \\
\hline \multicolumn{3}{|c|}{$\mathrm{BMI}=$ body mass index; $\mathrm{OR}=$ odds ratio. } \\
\hline \multicolumn{3}{|l|}{$\begin{array}{l}\text { a } P<.001 . \\
\text { в } P<.01\end{array}$} \\
\hline
\end{tabular}

BMI based on higher energy requirements, greater food consumption, and higher metabolic production. ${ }^{24,25}$ The current guidelines for water intake according to the Institute of Medicine adequate intake standards $(3.7 \mathrm{~L} / \mathrm{d}$ for adult men and 2.7 $\mathrm{L} / \mathrm{d}$ for adult women) are calculated independently of obesity status. ${ }^{25}$ In contrast, several methods of estimating fluid needs used in clinical settings are weight dependent, with estimated water requirements of healthy community-dwelling individuals to be between 40 and $50 \mathrm{~mL} / \mathrm{kg}$ a day. ${ }^{26}$ Using this estimate, the water requirements for a 5 -foot, 10 -inch man who weighs 160 pounds (healthy weight) and a 5 -foot, 10 -inch man weighing 210 pounds (obese) would differ by more than $1 \mathrm{~L}$. Clinicians are likely not aware of this greater water requirement among those with higher BMIs and thus may not provide adequate counsel-

Although causality and directionality cannot be established in our cross-sectional study, our findings suggest that additional investigation is warranted to examine the relationship between inadequate hydration and weight status. Inadequate hydration has been associated with worsened mental, physical, and emotional health. ${ }^{19}$ Performance in tasks that require attention, psychomotor, and immediate memory skills may be affected. ${ }^{20,21}$ Self-ratings of alertness and ability to concentrate have been shown to decline while ratings of tiredness and headache increase progressively when fluid intake is restricted to induce deficits of even as little as $1 \%$ to $2 \%{ }^{21}$ Poor mood, headaches, and renal dysfunction, as well as constipation, have also been associated with inadequate hydration. ${ }^{11,22}$

Though hydration is discussed in the context of weight management by clinicians and lay media, recommendations to remain adequately hydrated are not included in generally accepted guidelines as a treatment in weight management. ${ }^{23}$ Our findings suggest that adequate hydration may play a role in weight and prompt further discussion regarding adequate hydration during weight management counseling. If obese individuals are more likely to maintain poor hydration or are eating when they are actually thirsty, additional education could be provided regarding differentiating between cues of hunger and thirst.

Our findings also suggest that individuals with higher BMIs may behave in ways that lead them to be inadequately hydrated. Obese individuals have higher water needs than nonobese individuals, because water needs depend upon metabolic rate, body surface area, and body weight. ${ }^{24}$ Water turnover rates increase with ing to meet this requirement.

Although inadequate intake of water among obese adults may explain the observed findings, differential consumption of food with high water content may also contribute to the relationship between inadequate hydration and elevated BMI. Foods high in water or dietary fiber typically have fewer calories per gram and are thus lower in calorie density, whereas foods higher in fat are generally higher in calorie density. ${ }^{23}$ Although increasing fruits and vegetables is often recommended as part of a healthy weight management strategy and is not thought to be a stand-alone intervention for obesity, ${ }^{27}$ obese individuals and those with higher BMIs and increased hydration requirements may benefit from more guidance related to achieving adequate hydration through food and fluids.

Our study has several notable strengths, including the analysis of a nationally representative sample and the use of objective laboratory values of hydration and anthropometric measurements. Our findings, however, should be considered in the context of specific limitations. First, these data are cross-sectional and cannot be used to infer causation. Second, though urine osmolality is regarded as an excellent measure of hydration, it is possible that the 1-time reading available in the NHANES does not represent individuals' usual level of hydration. ${ }^{7}$ Studies have indicated, however, that this value is an adequate and accurate measure of hydration on a population level. ${ }^{11,28,29}$ Third, findings from our nationally representative sample of adults aged 18 to 64 years may not generalize to other age-groups (children, seniors) or to individuals in non-communitydwelling settings. Finally, because hydration is influ- 
enced by multiple factors, broad recommendations on methods to improve hydration may be difficult to make. This association between inadequate hydration and obesity, after controlling for confounding variables, has not previously been shown on a population level and suggests that water, an essential nutrient, may deserve greater focus in weight management research and clinical strategies.

To read or post commentaries in response to this article, see it online at http://www.annfammed.org/content/14/4/320.

Key words: hydration; obesity; body mass index; water; National Health and Nutrition Examination Survey

Submitted October 28, 2015; submitted, revised, February 15, 2016; accepted March 10, 2016.

Author contributors: Chang and Plegue conducted the analysis, and all 5 authors contributed to the conceptualization of the study and the writing of the article, including the revisions.

\section{References}

1. Ng M, Fleming T, Robinson M, et al. Global, regional, and national prevalence of overweight and obesity in children and adults during 1980-2013: a systematic analysis for the Global Burden of Disease Study 2013. Lancet. 2014;384(9945):766-781.

2. Swinburn BA, Sacks G, Hall KD, et al. The global obesity pandemic shaped by global drivers and local environments. Lancet. 2011;378 (9793):804-814

3. Roberto CA, Swinburn B, Hawkes $C$, et al. Patchy progress on obesity prevention: emerging examples, entrenched barriers, and new thinking. Lancet. 2015;385(9985):2400-2409.

4. Parretti HM, Aveyard P, Blannin A, et al. Efficacy of water preloading before main meals as a strategy for weight loss in primary care patients with obesity: RCT. Obesity (Silver Spring). 2015;23(9): 1785-1791.

5. Mattes RD. Hunger and thirst: issues in measurement and prediction of eating and drinking. Physiol Behav. 2010;100(1):22-32.

6. Daniels MC, Popkin BM. Impact of water intake on energy intake and weight status: a systematic review. Nutr Rev. 2010;68(9):505-521.

7. Armstrong LE. Challenges of linking chronic dehydration and fluid consumption to health outcomes. Nutr Rev. 2012;70(Suppl 2): S121-127.

8. Muckelbauer R, Sarganas G, Grüneis A, Müller-Nordhorn J. Association between water consumption and body weight outcomes: a systematic review. Am J Clin Nutr. 2013;98(2):282-299.

9. Dennis EA, Dengo AL, Comber DL, et al. Water consumption increases weight loss during a hypocaloric diet intervention in middle-aged and older adults. Obesity (Silver Spring). 2010;18(2):300-307.

10. Pan A, Malik VS, Hao T, Willett WC, Mozaffarian D, Hu FB. Changes in water and beverage intake and long-term weight changes: results from three prospective cohort studies. Int J Obes (Lond). 2013;37(10): 1378-1385.
11. Baron S, Courbebaisse M, Lepicard EM, Friedlander G. Assessment of hydration status in a large population. Br J Nutr. 2015; 113(1):147-58.

12. Centers for Disease Control and Prevention. National Health and Nutrition Examination Survey. http://www.cdc.gov/nchs/nhanes. htm. Accessed Feb 8, 2016.

13. Centers for Disease Control and Prevention. How is BMI calculated? http://www.cdc.gov/healthyweight/assessing/bmi/adult_bmi/index. html. Accessed Feb 8, 2016.

14. Kenney EL, Long MW, Cradock AL, Gortmaker SL. Prevalence of Inadequate Hydration Among US Children and Disparities by Gender and Race/Ethnicity: National Health and Nutrition Examination Survey, 2009-2012. Am J Public Health. 2015;105(8):e113-e118.

15. EFSA Panel on Dietetic Products, Nutrition and Allergies. Scientific opinion on dietary referemce values for water. EFSA Journal. 2010;8(3):1459.

16. Manz F, Wentz A. 24-h hydration status: parameters, epidemiology and recommendations. Eur J Clin Nutr. 2003;57(Suppl 2):S10-18.

17. Kant AK, Graubard BI. Contributors of water intake in US children and adolescents: associations with dietary and meal characteristics-National Health and Nutrition Examination Survey 20052006. Am J Clin Nutr. 2010;92(4):887-896.

18. Ogden CL, Carroll MD, Fryar CD, Flegal KM. Prevalence of obesity among adults and youth: United States, 2011-2014. NCHS Data Brief. 2015(219):1-8.

19. Popkin BM, D'Anci KE, Rosenberg $\mathrm{IH}$. Water, hydration, and health. Nutr Rev. 2010;68(8):439-458.

20. Adan A. Cognitive performance and dehydration. J Am Coll Nutr. 2012;31(2):71-78.

21. Maughan RJ. Impact of mild dehydration on wellness and on exercise performance. Eur J Clin Nutr. 2003;57(Suppl 2):S19-23.

22. Thomas DR, Cote TR, Lawhorne L, et al; Dehydration Council. Understanding clinical dehydration and its treatment. J Am Med Dir Assoc. 2008;9(5):292-301.

23. Dietary Guidelines for Americans 2010. Balancing calories to manage weight. http://www.fns.usda.gov/sites/default/files/Chapter2.pdf. Accessed Sep 24, 2015.

24. O'Connell BN, Weinheimer EM, Martin BR, Weaver CM, Campbell WW. Water turnover assessment in overweight adolescents. Obesity (Silver Spring). 2011;19(2):292-297.

25. Standing Committee on the Scientific Evaluation of Dietary Reference Intakes, Institute of Medicine, P.o.D.R.I.f.E.a.W. Dietary reference intakes for water, potassium, sodium, chloride and sulfate. Washington, DC: National Academies Press; 2004.

26. Vivanti AP. Origins for the estimations of water requirements in adults. Eur J Clin Nutr. 2012;66(12):1282-1289.

27. Rolls BJ, Ello-Martin JA, Tohill BC. What can intervention studies tell us about the relationship between fruit and vegetable consumption and weight management? Nutr Rev. 2004;62(1):1-17.

28. Cheuvront SN, Ely BR, Kenefick RW, Sawka MN. Biological variation and diagnostic accuracy of dehydration assessment markers. Am J Clin Nutr. 2010;92(3):565-573.

29. Armstrong LE, Maresh CM, Castellani JW, et al. Urinary indices of hydration status. Int J Sport Nutr. 1994;4(3):265-279. 